Artículo original

\title{
Una alarma nada excepcional: CRISPR/Cas9 y la edición de la línea germinal en seres humanos
}

\author{
An unsurprising alarm: CRISPR/Cas9 and the genetic editing of \\ the human germline
}

\section{Nahuel Pallitto* y Guillermo Folguera}

Instituto de Filosofía Dr. Alejandro Korn, Facultad de Filosofía y Letras, Universidad de Buenos Aires, CONICET, Buenos Aires, Argentina

\section{Resumen}

En este artículo analizamos el nacimiento de los primeros seres humanos editados genéticamente mediante la tecnología CRISPR/Cas9 desde una perspectiva que contempla las condiciones de posibilidad que lo han habilitado e impulsado. En contra de los abordajes ofrecidos hasta el momento por la bioética, el trabajo brinda una lectura que no reduce el evento a un mero acto de desobediencia individual, sino que lo concibe como el resultado esperado de ciertas lógicas epistémicas, institucionales, políticas y económicas de la tecnociencia. A su vez, reflexionamos acerca del rol que ha asumido la bioética frente al avance de CRISPR/Cas9 y las respuestas que ha otorgado ante el conocimiento de su aplicación en embriones humanos. Concluimos el artículo sugiriendo que el modelo de la bioética basado en la heteronomía y el control externo

\footnotetext{
* Autor para correspondencia.

Correo electrónico: nahuelpallitto@gmail.com (N. Pallitto).
} 
de la ciencia y la tecnología no resulta significativo ni eficaz en el contexto señalado, a la par que proponemos como alternativa un enfoque sistémico.

(C) 2020 Centros Culturales de México, A.C. Publicado por Masson Doyma México S.A. Todos los derechos reservados.

Palabras clave: Bioética; Edición genómica; CRISPR/Cas9; Condiciones de posibilidad; Enfoque sistémico

Abstract: In this article, an analysis is presented on the birth of the first human beings subjected to an embryonic genetic modification using CRISPR/Cas9 technology from a perspective that considers the conditions that has led to its emergence. As opposed to the approaches presented so far by bioethics, an alternative account is presented that does not reduce the event to an act of individual disobedience, but rather conceives it as the expected result of certain epistemic, institutional, political, and economic dimensions of technoscience. Moreover, thoughts are presented on the role assumed by bioethics with regards to CRISPR/Cas9 and the response it has provided to its application in human embryos. It is concluded by suggesting that the model of bioethics based on heteronomy and the external control of science and technology is neither significant nor effective in the indicated context, with an alternative systemic approach being provided.

(C) 2020 Centros Culturales de México, A.C. Published by Masson Doyma México S.A. All rights reserved.

Keywords: Bioethics; Genome editing; CRISPR/Cas9; Conditions of possibility; Systemic approach

\section{Introducción}

A fines de noviembre del 2018 una noticia proveniente de China disparó las alarmas de la comunidad científica, de los profesionales de la bioética y de la sociedad en su conjunto. El investigador He Jiankui de la Universidad del Sur de Ciencia y Tecnología en Shenzhen anunció el nacimiento de los dos primeros seres humanos editados genéticamente. Cuando las gemelas Lulu y Nana no eran más que unas pocas células embrionarias, sus genomas fueron intervenidos con la supuesta intención de evitar que el virus del HIV pudiera ingresar a sus cuerpos. A la edición genética embrionaria le acompañaron los protocolos aceptados y estandarizados de la fertilización in vitro, los cuales concluyen con la implantación de los embriones en el útero materno.

La noticia de la edición genética de la línea germinal humana generó repercusiones internacionales. Cabe recordar que en la mayoría de los países del mundo, 
incluido China, ese tipo de procedimientos se encuentra prohibido (Wang et al., 2019; Zhang y Lie, 2018). A su vez, junto con los aspectos legales, se proclamó que el experimento realizado violó diversos principios éticos vinculados con la seguridad y eficacia de la tecnología empleada, al mismo tiempo que no contempló adecuadamente el balance entre los riesgos involucrados y los beneficios potenciales (Ma, Zhang y Qin, 2019; Zhang, Chen, Yi, Tang y Wang, 2019). De este modo, se configuró una respuesta de repudio prácticamente unánime ante lo que algunos consideran que ha sido una de las infracciones éticas más notorias que se han registrado en las ciencias médicas desde la Segunda Guerra Mundial (Krimsky, 2019).

El énfasis puesto en el incumplimiento de los acuerdos y consensos preestablecidos sugiere el modo principal en que las voces críticas han, hasta aquí, interpretado y analizado el caso: se trata de un evento anómalo que debe ser entendido en términos del (mal)obrar de un sujeto individual (Charo, 2019; Krimsky, 2019). Desde esta perspectiva, la aparición inesperada de los primeros seres humanos editados genéticamente se explica por el aparente comportamiento temerario e irresponsable de He Jiankui, un científico-investigador que obró en direcciones contrarias a las estipuladas por los acuerdos científicos y las normativas bioéticas internacionales (Davies, 2018; Krimsky, 2019; Organizing Committee of the Second International Summit on Human Genome Editing, 2018). De este modo, tanto las reacciones como las respuestas se han centrado básicamente en la acción indebida e inesperada de un infractor individual o, en todo caso, incluyendo también a quienes lo acompañaron durante el experimento. De hecho, tanto el gobierno de China como la Universidad del Sur de Ciencia y Tecnología de Shenzhen han declarado desconocer y oponerse a la polémica investigación, reforzando así la imagen de un individuo actuando en desobediencia (Normile, 2018).

Sin embargo, si no se quiere correr el riesgo de reducir la ética a un juego entre buenos y malos u obedientes y desobedientes, la lectura centrada en la transgresión individual requiere ser problematizada desde una perspectiva que contemple que todas las elecciones y acciones científicas y tecnológicas se encuentran situadas política y socialmente (Digilio, 2017; Pestre, 2005). Este reconocimiento implica que no puede mantenerse apartado aquello que los investigadores realizan de las condiciones sociales y políticas de su emergencia. A su vez, significa que una comprensión cabal de un acontecimiento como el que aquí nos ocupa precisa atender en simultáneo tanto a los factores internos como a aquellos contextuales que estructuran y condicionan las prácticas científicas y tecnológicas. Lo dicho se traduce en la necesidad de analizar a qué tipo de lógicas de producción y uso del conocimiento científico y tecnológico responden las acciones de los directamente involucrados, de 
modo tal de poder identificar qué razones, valores y finalidades predominan, así como las realidades epistémicas, institucionales, políticas y económicas que las orientan y les dan sentido.

El objetivo principal de este artículo consiste en identificar y caracterizar algunas condiciones de posibilidad generales que sustentaron, habilitaron y fomentaron el primer evento de edición genética de la línea germinal humana. Por condiciones de posibilidad nos referimos al conjunto de factores que configuran la matriz o el estado general de una práctica científica y tecnológica, a la vez que influyen en las lógicas dominantes que subyacen a su producción y uso. En ese sentido, el trabajo procura establecer y profundizar en el vínculo entre dicha matriz de posibilidades y el evento analizado, a modo de sugerir una lectura alternativa a las ofrecidas hasta el momento por el campo de la bioética. Como se desprende del objetivo principal, la intención es adquirir una comprensión integral del evento que no se agote en los nombres propios ni se limite a reconocer, señalar y asignar infractores.

Para tal fin, comenzaremos nuestro recorrido describiendo la tecnología CRISPR/Cas9 y el modo en que fue utilizada por He Jiankui en la edición de los embriones humanos. En segundo lugar, identificaremos y exploraremos una serie de elementos que, a nuestro entender, configuran la matriz de posibilidades o el escenario para el desarrollo e implementación de la tecnología en cuestión. En una tercera instancia, ofreceremos unas breves reflexiones acerca del rol que ha asumido la bioética frente al avance de CRISPR/Cas9 y las respuestas que ha brindado ante el conocimiento de su aplicación en embriones humanos, problematizando ambos aspectos. En un cuarto momento, sugeriremos una mirada alternativa de la bioética basada en un enfoque sistémico. Por último, finalizaremos con un conjunto de consideraciones que sugieren que el evento puntual que aquí se analiza es parte de una matriz tecnocientífica de alcance global cuyas finalidades, valores y prácticas promueven antes que desalientan acontecimientos similares. De este modo, nuestra conclusión principal es que, contrariamente a lo que se señala, la alarma que resonó mundialmente con tanta vehemencia en noviembre del 2018, lejos de ser excepcional, exhibe fuertes influencias de las condiciones de posibilidad globales que se han montado en torno a la ciencia y la tecnología.

\section{¿Qué es CRISPR/Cas9? ¿Cómo funciona y para qué fue aplicado?}

La modificación de la línea germinal humana fue posible mediante una tecnología conocida como CRISPR/Cas9. Esta herramienta surge de la modificación y 
adaptación de un sistema de defensa inmunitario presente en ciertos procariotas que les permite a estos microorganismos detectar y degradar el ADN de virus y plásmidos invasores (Doudna y Charpentier, 2014; Hsu, Lander y Zhang, 2014; Lander, 2016). El término CRISPR refiere a una región del genoma que conserva registros moleculares de infecciones virales pasadas y que opera junto con otros genes asociados (Cas es una abreviación del inglés CRISPR-associated genes) en las respuestas inmunitarias de estos seres vivos.

En su versión tecnológica más frecuente, los sistemas CRISPR/Cas han sido simplificados y transformados en un único complejo molecular formado solamente por dos elementos: una molécula de ARN denominada sgARN (single guide ARN) y una enzima conocida como Cas9 (Ma et al., 2019; Sternberg y Doudna, 2015) ${ }^{1}$. La molécula sgARN puede ser diseñada en laboratorios para reconocer secuencias específicas de ADN en un genoma de interés que se desee modificar. El mecanismo de reconocimiento se basa en la complementariedad de bases entre el sgARN y la secuencia de ADN a intervenir (Doudna y Charpentier, 2014). La enzima Cas9 es una endonucleasa que puede introducir cortes en la cadena de ADN en aquellas regiones reconocidas por la molécula sgARN (Jinek et al., 2012). En el caso de las bacterias esos cortes sirven para eliminar las moléculas de ADN invasoras. Sin embargo, fuera de las células procariotas, la capacidad de Cas9 de introducir cortes es aprovechada para realizar cambios genéticos, ya sea que estas modificaciones impliquen la eliminación o incorporación de un gen, el reordenamiento de un cromosoma o bien la corrección de una variante genética (Sternberg y Doudna, 2015). En este último caso, se le debe incorporar una tercera molécula de ADN al complejo conformado por las moléculas de sgARN y Cas9, la cual sirve de molde para corregir o suplantar la secuencia anterior (Rong, Zhu, Xu y Fu, 2014; Sternberg y Doudna, 2015).

A pesar de la relevancia social y ambiental que tienen las aplicaciones mencionadas y a que el sistema CRISPR/Cas9 ya había sido utilizado previamente en células embrionarias humanas (Liang et al., 2015), la aplicación que ha puesto en el centro de la escena a la tecnología CRISPR/Cas9 ha sido la realizada por el investigador He Jiankui. Junto a un equipo de colaboradores, el investigador modificó el ADN de dos embriones humanos para evitar la expresión de un correceptor de membrana presente en células del sistema inmunitario (Normile, 2018). Según estudios previos, este correceptor se encuentra involucrado en la susceptibilidad humana a la infección por HIV (Choe et al., 1996; Lederman, Penn-Nicholson, Cho y Mosier, 2006).

\footnotetext{
${ }^{1}$ Existen variantes tecnológicas que utilizan otros elementos de los sistemas CRISPR/Cas y que agregan matices a la descripción que aquí ofrecemos (ver, por ejemplo, Wright, Nuñez y Doudna, 2016).
} 
De acuerdo a la explicación ofrecida en el Segundo Encuentro Internacional de Edición del Genoma Humano, el grupo de investigación diseñó un sgARN complementario a una secuencia del gen del correceptor CCR5 y luego inyectó el complejo sgARN/Cas9 a un conjunto de embriones, obteniendo como resultado la eliminación de parte de dicha secuencia en al menos dos de ellos (Ma et al., 2019). Con esta modificación la investigación buscó la pérdida de funcionalidad del correceptor con la consiguiente pretendida inmunidad específica al $\mathrm{HIV}^{2}$.

Así fue generado el primer evento de edición genética reportado en el que los embriones editados fueron implantados con fines reproductivos y cuyo embarazó llegó a término. Su importancia y singularidad no implica, sin embargo, que su origen no responda a contextos más generales, condiciones que lo hacen posible y lógicas dominantes que actúan. De algunos de estos elementos nos ocuparemos a continuación.

\section{Imperativo tecnológico y condiciones de posibilidad}

Más allá de los nombres propios y del momento en que se hizo público el acontecimiento, resulta clave reconocer cómo detrás de la investigación y su anuncio se encuentra orientando y estructurando la práctica una matriz que tiene como regla privilegiada el imperativo tecnológico.

En una de sus caracterizaciones más frecuentes, el imperativo tecnológico señala que todo lo que sea técnicamente posible debe ser realizado (Agazzi, 1996; Linares, 2008). Lo tecnológico se presenta así como solución indiscutida de todo problema humano, desestimando cualquier tipo de cuestionamiento. En el caso particular de CRISPR/Cas9, el imperativo tecnológico se reconoce con suma claridad. Por ejemplo, recuperando las palabras de Jennifer Doudna, una de las creadoras de la tecnología: «La pregunta, comenzaba a entender, no era si la edición genética sería utilizada para alterar el ADN en células germinales humanas, sino cuándo y cómo»

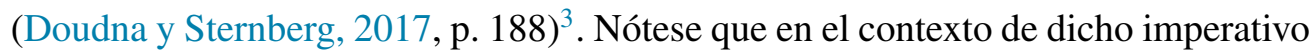
la bioética no puede asumir sino un rol tardío, una vez que la tecnología ha sido ya

\footnotetext{
${ }^{2}$ Uno de los principales problemas señalados por algunos críticos es que dicho correceptor presenta funciones celulares diversas que se verían afectadas por su eliminación en modos desconocidos y posiblemente perniciosos (Ma et al., 2019; Zhou et al., 2016).

${ }^{3}$ The question, I was beginning to realize, was not if gene editing would be used to alter DNA in human germ cells but rather when, and how.
} 
desarrollada y montada; un rol limitado a delinear el camino a la traducción clínica (Dyer, 2018).

Pero antes de profundizar en las implicancias del imperativo tecnológico para la bioética, debemos brindar algunos elementos que nos permitan entender de qué se trata la matriz que establece las condiciones de posibilidad de un evento como el que aquí nos convoca. Esto es objeto de las siguientes subsecciones, en las que presentaremos las principales dimensiones que involucra este esquema común y que dista de ubicar a los investigadores chinos como los únicos actores en juego; una matriz que comprende elementos epistémicos, económicos y políticos.

\section{La racionalidad tecnocientífica}

Uno de los aspectos determinantes de la matriz de posibilidades es el tipo de racionalidad que orienta y define las finalidades de las investigaciones científicas y tecnológicas. La imagen más extendida es la que considera que en las ciencias predomina un tipo de racionalidad logocéntrica y que el mejor modelo que describe la relación de estas con la tecnología es de tipo lineal (Echeverría, 2003; Linares, 2008). En el marco general de un pensamiento logocéntrico, el objetivo primario de las ciencias consiste en generar descripciones objetivas y empíricamente adecuadas del mundo, de modo tal de contribuir a una mejor comprensión de nuestros entornos naturales y sociales (Kitcher, 2001; Laudan, 1984). Así, se establece un ordenamiento «natural» en el cual las ciencias primero descubren y luego justifican racionalmente las hipótesis y teorías que elaboran en colaboración con las comunidades científicas de las que forman parte.

Aunque la descripción del mundo constituye el motor fundamental de la racionalidad logocéntrica, su lógica también admite que, en algunos casos, los saberes elaborados puedan ser utilizados para transformar aspectos de nuestras realidades. Cuando eso sucede, el conocimiento se convierte en sustento de desarrollos tecnológicos y cumple una función aplicada (Bunge, 1966; Klimovsky, 1994). Así se completa uno de los modelos clásicos en el cual las ciencias primero descubren, luego justifican y, por último, aplican las tecnologías que han surgido de ese proceso racional que persigue la verdad. En ese mundo revelado gracias a una racionalidad logocéntrica, las tecnologías se conciben como meros instrumentos a nuestra disposición, simples medios para los fines humanos (Linares, 2008). 
No obstante, esta conceptualización de la práctica científica ha sido complementada con otra que considera una racionalidad de tipo tecnocientífico $o$ pragmático-tecnológico (Linares y Ayestarán, 2010; Pallitto y di Pasquo, 2017). Los objetivos y los valores científicos imperantes no se vinculan ya con la descripción o comprensión de nuestras realidades naturales y sociales, sino más bien con su dominio, control y manipulación. Lo tecnológico pierde así su carácter meramente instrumental para convertirse en un mediador universal de nuestras acciones y relaciones (Linares, 2008).

El predominio de una racionalidad de tipo tecnocientífico en el desarrollo y uso de CRISPR/Cas9 puede apreciarse en uno de los recientes relatos acerca de su historia realizado por dos de sus principales protagonistas:

A medida que los científicos iban utilizando CRISPR para editar los genes de más y más animales, y mientras continuaban expandiendo las capacidades de la herramienta, me percaté de que no pasaría mucho tiempo hasta que los investigadores probaran CRISPR en óvulos, esperma o embriones humanos con el objetivo de reescribir permanentemente el genoma de futuros individuos. Pero, increíblemente, nadie estaba discutiendo esta posibilidad [...] Incluso cuando el campo de CRISPR estaba explotando, nadie por fuera de mi círculo de colegas parecía saberlo o entender lo que se aproximaba (Doudna y Sternberg, 2017, pp. 197-198) ${ }^{4}$.

De más está decir que nuestro objetivo aquí no es negar que CRISPR/Cas9 puede presentar numerosas aplicaciones interesantes e importantes, sino comprender cómo su desarrollo responde a una lógica de investigación en la cual lo tecnológico abandona su carácter de mero instrumento para devenir telos indiscutible de la actividad científica, una finalidad en sí misma. En ese credo que recurre al progreso tecnológico como conjuro contra los males de la humanidad habita la aparente inexorabilidad de CRISPR/Cas9 a la que hacen referencia una y otra vez sus defensores.

\footnotetext{
${ }^{4}$ As scientists used CRISPR to edit the genes of more and more animals, and as they continued to expand the tool's capabilities, I realized it would not be long before researchers somewhere tested CRISPR on human eggs, sperm, or embryos with the goal of permanently rewriting the genome of future individuals. But incredibly, no one was discussing this possibility [...] Even as the CRISPR field was exploding, no one outside of my circle of colleagues seemed to know about it or understand what was coming.
} 
Publicidades: las promesas como horizonte y la omisión de riesgos

Íntimamente ligados a la racionalidad tecnocientífica se hallan el lenguaje y la práctica publicitaria que han atravesado todos los proyectos tecnocientíficos en las últimas décadas. Se trata de un mismo movimiento en el que se multiplican las promesas de los desarrollos científicos y tecnológicos mientras se omiten sus potenciales riesgos. En efecto, las promesas asociadas a la resolución de problemas sociales y naturales han sido un sostén fundamental para que el imperativo tecnológico pueda regir. Una vez más, en palabras de Doudna, nuevamente junto a Sternberg (Doudna y Sternberg, 2017, p. xix):

Estoy increíblemente entusiasmada con la promesa de la edición de genes. La investigación en CRISPR continúa progresando enérgicamente tanto en los laboratorios académicos como en las nuevas empresas de biotecnología, estando las últimas respaldadas por más de mil millones de dólares de inversores y empresas de capital de riesgo ${ }^{5}$.

Promesas se esgrimen, aunque de muy diferente tipo. En el caso particular de la tecnología CRISPR/Cas9 las mismas abarcan desde avances en la investigación básica (Liang et al., 2015), pasando por la búsqueda de soluciones a numerosas enfermedades con base genética (Maddalo et al., 2014; Platt et al., 2014; SánchezRivera et al., 2014) hasta la propia producción de nuevas tecnologías (Wright et al., 2016) y su aplicación en agricultura (Gao, 2018). En oposición, poco se discuten los riesgos y peligros asociados por parte de aquellas personas que utilizan dicho lenguaje publicitario. Para reconocer algunos de estos riesgos hay que recurrir a otros autores, tales como Gumer (2019), quien se opone a la edición genética de la línea germinal humana reconociendo que «el gen escogido puede también desempañar múltiples funciones, de modo tal que su eliminación podría afectar tanto procesos beneficiosos, así como patológicos. En consecuencia, incluso los intentos exitosos de edición de un cierto gen pueden impactar de manera negativa en la salud de formas que todavía no hemos entendido (p. 139) ${ }^{6}$. O también a Lanphier, Urnov,

\footnotetext{
${ }^{5}$ I'm incredibly enthusiastic about the promise of gene editing. Progress in CRISPR research continues briskly in both academic labs and startup biotechnology companies, the latter supported by more than a billion dollars from investors and venture capital firms.

${ }^{6}$ A targeted gene may also play multiple roles such that its elimination could affect beneficial, as well as pathological, processes. Consequently, even successful attempts to edit a certain gene may negatively impact health in ways that we have yet to understand.
} 
Haecker, Werner y Smolenski (2015), quienes hace algunos años advertían que la edición genómica en embriones humanos podría tener efectos impredecibles en las generaciones futuras, volviéndolo sumamente peligroso e inaceptable éticamente.

\section{La innovación y el carácter empresarial}

Un tercer aspecto que considerar se vincula con el fuerte giro de las investigaciones dado hacia el mercado en las últimas décadas, a partir del cual la tecnociencia pasa a ser fundamentalmente valorada por su capacidad de innovación y transferencia al sector empresarial. Debido a la exigencia y compulsión por lanzar nuevos productos al mercado, los valores económicos impregnan y orientan las acciones tecnocientíficas:

En estos días se espera (y de hecho lo exige la ley) que los descubrimientos financiados con fondos públicos con potencial económico se comercialicen: la ciencia, desde esta mirada, sirve mejor al bien público al llevar bienes al mercado. CRISPR no es una excepción [...] La aparente inevitabilidad de las aplicaciones CRISPR para editar embriones da por sentado toda la economía de la innovación biomédica, bajo el supuesto de que el impulso para comercializar es, por definición, un bien universal (Jasanoff, Hurlbut y Saha, 2015, p. 28) ${ }^{7}$.

La promesa por generar innovaciones es en la actualidad uno de los motores más claros de inversión en la actividad tecnocientífica, sustentada por la idea de la ganancia económica y el patentamiento (Contreras y Sherkow, 2017; Sherkow, 2016, 2018). Si bien la innovación tiene una importante diversidad de acepciones, existen ciertas referencias comunes. En la versión de Joseph Alois Schumpeter, uno de los considerados «padres» del concepto de innovación, esta se entiende como «la permanente creación de productos nuevos o formas nuevas de producir, regular u organizar la producción» (Bianchi, 2006, p. 34). Sin embargo, tal como señala Mario Albornoz (2009), la innovación no es meramente un acto de invención, pues mientras esta es un acto de creatividad intelectual, la innovación es una decisión económica.

\footnotetext{
${ }^{7}$ These days it is expected (and indeed required by law) that publicly funded discoveries with economic potential should be commercialized: science, in this view, best serves the public good by bringing goods to market. CRISPR is no exception [...] The apparent inevitability of CRISPR applications to editing embryos takes for granted the entire economics of biomedical innovation, with the assumption that the push to commercialize is by definition a universal good.
} 
También en la definición de la OCDE la innovación es asociada directamente al éxito comercial (OCDE, 1996).

Presentar a la innovación como objetivo prioritario de las prácticas tecnocientíficas significa generar desde y para el mercado, por lo que los aspectos anteriores vinculados con la racionalidad y el discurso publicitario cobran formas muy significativas. Por ejemplo, las instituciones asociadas a la producción tecnocientífica -más allá de si pertenecen o no a Estados - asumen un notorio carácter de corte empresarial en el que el triunfo económico actúa como principal criterio de autorreproducción y éxito. Asimismo, junto con la alteración de la naturaleza de las instituciones, los propios científicos asumen este mismo carácter mixto (Larrión Cartujo, 2011), estableciéndose así un vínculo estrecho entre las instituciones estatales, los actores científicos y las propias empresas bajo el norte de los sistemas de innovación (Sharif y Tang, 2014).

Este mismo esquema puede ser también reconocido en el caso de CRISPR/Cas9 que aquí nos convoca. Por un lado, las instituciones estatales vinculadas con CRISPR/Cas9 han buscado capitalizar la tecnología mediante una serie de acuerdos de licencia con empresas comerciales (Contreras y Sherkow, 2017), mientras que, por otro lado, surgen fuertes inversiones que asumen un carácter de tipo global:

[...] los inversores han volcado más de mil millones de dólares en las diversas nuevas compañías que buscan herramientas de biotecnología basadas en CRISPR y terapias médicas [...] Tres empresas emergentes de terapia, dos con sede en Cambridge, Massachusetts, y una en Basilea, Suiza, han sido cofundadas por científicos académicos, incluidos Emmanuelle y yo, y han sido ayudadas por cientos de millones de dólares de capitales de riesgo (Doudna y Sternberg, 2017, p. 182) ${ }^{8}$.

En todos los casos se trata de historias en donde los Estados y las empresas se mezclan, acuerdan y compiten.

\footnotetext{
${ }^{8}[$ [. . ] investors have poured well over a billion dollars into the various startup companies that are pursuing CRISPRbased biotechnology tools and medical therapeutics [...] Three startup therapeutics companies, two based in Cambridge, Massachusetts, and one in Basel, Switzerland, have been co-founded by academic scientists, including Emmanuelle and me, and aided by hundreds of millions of dollars in venture capital backing.
} 
Como era de esperar, estas lógicas también son reproducidas por He Jiankui. Merece la pena destacar sus palabras: «La generosidad de Shenzen para fomentar empresas incipientes, especialmente la de los capitalistas de riesgo, es la razón principal que me atrajo [. . . ] No soy un profesor en el sentido tradicional. Prefiero ser un investigador-emprendedor»? (He Jiankui, 2018, en Beijing Review. Último acceso: noviembre 2019) ${ }^{9}$. Si bien desconocemos cuáles fueron los motivos reales que llevaron al investigador a editar el genoma de los embriones humanos — solo él los conoce-, no podemos dejar de señalar las lógicas empresariales que posiblemente influenciaron sus acciones.

\section{Asuntos geopolíticos y la puja entre Estados}

Para finalizar, resulta necesario considerar un último aspecto que nos permita comprender tanto el «apuro» de He Jiankui, así como las críticas de muchos de sus detractores: la competencia global. En un artículo reciente, Smriti Mallapaty (2018) señaló que el gobierno chino reconoce la importancia de las biociencias en su competitividad geopolítica, siendo consideradas áreas estratégicas la biomedicina, la biología sintética y las técnicas de medicina regenerativa ${ }^{10}$. Tal como sugiere Cao Cong, un investigador de estudios en innovación de la Universidad de Nottingham Ningbo China: «China no quiere perderse la revolución biotecnológica de las ciencias de la vida» (en Mallapaty, 2018, p. s66) ${ }^{11}$.

Este movimiento del Estado chino tiene como contraparte el propio de Estados Unidos, configurándose entre ambas potencias tecnocientíficas una guerra económica que enmarca el evento de interés. En efecto, se trata de un conflicto económico en el cual se espera que los motores del desarrollo, entre los cuales figuran la ciencia y la tecnología, presenten implicancias directas. Esta batalla ha involucrado numerosas medidas económicas y políticas, como las vinculadas con los aranceles en productos importados.

CRISPR/Cas9 y la modificación genética, lejos de ser aspectos marginales de estos asuntos, constituyen elementos centrales. Por ejemplo, Carl June, médico y profesor de la Universidad de Pennsylvania, señaló en un editorial de la revista

\footnotetext{
${ }^{9}$ Shenzhen's generosity in encouraging startups, especially venture capitalists is the main reason that attracted me [...] I am not a professor in the traditional sense. I prefer to be a research-type entrepreneur.

10 Tales áreas estratégicas e industriales figuran en el 13. ${ }^{\circ}$ Plan Quinquenal de China (Mallapaty, 2018).

11 China doesn't want to miss the life-science biotech revolution.
} 
Nature que esta tecnología «va a desencadenar "Sputnik 2.0", un duelo biomédico en progreso entre China y los Estados Unidos» (June en Cyranoski, 2016, p. 479) ${ }^{12}$. Más allá del nuevo actor geopolítico que representa China, la configuración del acontecimiento como si se tratase de una «carrera» presenta ciertas similitudes con el caso histórico, poniendo en juego en esta oportunidad quién será el primero en llevar la tecnología a la clínica o el mercado (Normile, 2017).

Hemos así presentado algunos elementos que forman parte de la matriz tecnocientífica de posibilidades que habilitó y fomentó el primer evento de edición genómica en embriones humanos que fueron implantados y cuyo embarazo llegó a término. A continuación, algunas consideraciones generales relativas al rol específico de la bioética en este evento.

\section{CRISPR/Cas9 y las respuestas de la bioética}

¿De qué modo participó el campo de la bioética en el contexto previamente señalado? Para poder brindar una respuesta atinada a dicho interrogante conviene comenzar comentando algunos aspectos de su reciente historia. Desde que la bioética se conformó como un campo profesional en la década de 1970, ha adoptado como una de sus tareas fundamentales la elaboración de normas éticas y jurídicas universales que aspiran a ejercer un límite y un control de los potenciales abusos de las ciencias y las tecnologías (Saada, 2008). Esta aspiración se ha traducido en numerosas disposiciones, principios, guías, protocolos, regulaciones y leyes que de alguna manera establecen lo que está permitido o es deseable y aquello que se encuentra prohibido o es indeseable. Como consecuencia, se ha ido afianzando un proceso de externalización de la ética que implica que los investigadores no requieren internalizar los preceptos éticos porque estos son elaborados por un conjunto de expertos dedicados a su elaboración y formalización (Digilio, 2017; Rose y Rose, 2013).

En el caso de la edición genética de la línea germinal humana, la concepción de una ética basada en la heteronomía o en la imposición de reglas se expresa con suma claridad. Previamente al anuncio de He Jiankui, el campo ya contaba con ciertos acuerdos y consensos internacionales respecto a la permisibilidad de modificar los embriones de nuestra especie (Baltimore et al., 2015; Dickenson y Darnovsky, 2019; Organizing Committee of the Second International Summit on Human Genome

$\overline{12}[\ldots]$ is going to trigger 'Sputnik 2.0', a biomedical duel on progress between China and the United States. 
Editing, 2018). Asimismo, la mayoría de los países con los medios tecnocientíficos apropiados disponían también de regulaciones prohibitivas respecto a la transferencia de esos embriones al sistema reproductivo humano, incluyendo a China (Krimsky, 2019; Zhang y Lie, 2018).

A su vez, la idea de la importancia y predominio de una ética externa y heterónoma se refuerza a partir de las reacciones que ha manifestado la comunidad científica internacional. En conformidad con las ideas expresadas en los párrafos precedentes, se sugirió que los abusos como los de He Jiankui deben corregirse o evitarse formulando mejores regulaciones y garantizando controles más estrictos por parte de las entidades de supervisión correspondientes. Así, por ejemplo, la Academia China de Ciencias Médicas manifestó que «se necesitan de más pautas prácticas para las tecnologías emergentes» (Wang et al., 2019, p. 26) ${ }^{13}$, mientras que la Academia China de Ingeniería declaró que «es hora de formular la legislación, las leyes, los reglamentos y las directrices pertinentes, y realizar modificaciones adaptativas según sea necesario para establecer sistemas de supervisión enfocados en evitar cualquier uso técnico inapropiado de esta tecnología» (Zhang et al., 2019, p. 25) ${ }^{14}$. En ambos casos, las soluciones sugeridas apuntan en una misma dirección, esto es, hacia el desarrollo y perfeccionamiento de normas y pautas de conducta para los investigadores.

Ahora bien, ¿cuál es la pertinencia y eficacia de una ética basada en la regulación externa de las prácticas tecnocientíficas? Una respuesta inmediata, en vista de los acontecimientos más recientes, es que su pertinencia y eficacia son bajas o negativas, ya que no ha conseguido cumplir con sus objetivos declarados, aunque ha conducido a creer lo contrario. Los primeros seres humanos editados genéticamente han nacido a pesar de las normativas y las prohibiciones generalizadas; el equipo de investigación involucrado ha manipulado e implantado los embriones modificados en contra de numerosas declaraciones, informes y principios internacionales ${ }^{15}$. Si bien puede ser cierto que en algunos países la fuerza coercitiva de esas normativas resulte débil o presente ciertas ambivalencias, lo cierto es que las comunidades científicas y tecnológicas ya contaban con los acuerdos éticos y legales básicos formalizados.

La cuestión que debemos atender, entonces, reside en comprender ese fracaso y brindar ciertos elementos interpretativos que nos permitan entender por qué la

\footnotetext{
$\overline{13}$ [...] more practical guidelines are necessary for emerging technologies.

${ }^{14}$ It is time to formulate relevant legislation, laws, regulations, and guidelines, and make adaptive amendments as necessary to establish focused supervisory systems to avoid any inappropriate technical uses of this technology.

15 El propio He Jiankui publicó un artículo sobre los aspectos éticos de CRISPR que incumplió meses después (Jiankui, Ferrell, Yuanlin, Jinzhou y Yangran, 2018).
} 
bioética está condenada a cumplir una función retórica y ornamental frente a los desarrollos tecnocientíficos si no asume estrategias de acción diferentes. Y el problema fundamental, a nuestros ojos, es que la bioética se ha convertido en una búsqueda compulsiva de normas que resulta funcional al mundo social ya constituido en lugar de asistir al ser humano en su capacidad de reflexión transformadora (Rose y Rose, 2013). Lo que exige es obediencia antes que pensamiento crítico. Así lo expresa, por ejemplo, Patricia Digilio (2017, p. 30):

Una ética basada en la heteronomía se parece más a una forma de represión y de violencia que al ejercicio de una elección voluntaria. Si no hay una apropiación vital del precepto moral éste se experimenta como coerción externa sobre la propia libertad y particularidad o bien como una regla a seguir sin demasiada convicción $[\ldots]$.

Con esas palabras la autora nos recuerda que la ética no puede complacerse únicamente con normas e indicaciones acerca de cómo debemos proceder porque esta depende de un ejercicio reflexivo inalienable, un acercamiento al fundamento de nuestras acciones que no puede transferirse sin sufrir pérdidas esenciales. En ese sentido, la ética nunca puede ser concebida como algo totalmente externo a las comunidades científicas y tecnológicas. De poco sirven las vías normativas y reglamentarias si los sujetos que son parte de los desarrollos tecnocientíficos han suspendido su capacidad de juicio; si no son capaces, como sugería Hanna Arendt (2009 [1958]), de pensar en lo que, sin embargo, son capaces de hacer. Esa separación entre conocimiento (know-how) y pensamiento nos convierte en «irreflexivas criaturas a merced de cualquier artefacto técnicamente posible, por muy mortífero que fuera» (ibid. pp. 15-16). En efecto, es esa misma disociación la que permite que la ciencia se haya convertido en un medio de la técnica (Ellul, 1964 [1954]) y que, entonces, resulte perfectamente posible y natural poner en marcha los dispositivos tecnológicos sin una idea clara de cuáles son las finalidades perseguidas. $\mathrm{O}$ en el caso que nos compete, modificar genéticamente embriones humanos solo porque disponemos de los medios tecnológicos para hacerlo.

\section{Un enfoque sistémico}

En función de lo hasta aquí discutido, resulta necesario exponer brevemente lo que consideramos que es una alternativa más prometedora para la bioética. Por motivos de espacio, no puede más que tratarse de un esbozo de una propuesta que requiere 
de una elaboración más cuidada y elaborada ${ }^{16}$. Pero antes debemos realizar una aclaración importante y necesaria acerca de las reflexiones desarrolladas en este trabajo. En ningún momento hemos intentado sugerir que el acontecimiento científico y tecnológico presentado implica alguna forma de determinismo sociológico absoluto de la tecnociencia. Por el contrario, tal como la alternativa que describiremos sucintamente sostiene, el caso tratado, así como el rol de la bioética, pueden ser mejor comprendidos si se adopta un enfoque sistémico. Desde esta perspectiva, «la actividad científica puede ser concebida como un sistema de comportamientos y de acciones inserto en un cierto medio ambiente, del cual sufre la acción, y al mismo tiempo reacciona a este influjo modificando a su vez este ambiente» (Agazzi, 1996, p. 305). Así, ciencia y tecnología son considerados subsistemas abiertos y adaptativos de un sistema social más amplio en el cual entran en relaciones mutuas de input, output y feedback con otros subsistemas sociales y no sociales (Agazzi, 1987, 1996). Siguiendo la perspectiva sistémica, los factores que hemos reconocido en este artículo pueden ser interpretados como inputs que demandan de la ciencia y la tecnología ciertos saberes y productos, estos últimos a la vez entendidos como outputs de dichas actividades. En ese sentido, la edición genómica llevada a cabo en embriones humanos se presenta como una respuesta a ciertas demandas sociales realizadas sobre los sistemas científicos y tecnológicos.

La bioética entra a formar parte de estos procesos de input, output y feedback de una manera análoga a las influencias que hemos destacado, debiendo ser considerada como otro subsistema social que genera sus propias influencias sobre todos los demás subsistemas de una sociedad dada, a la vez que recibe de estos sus influjos respectivos. No se trata, entonces, de pensar que la bioética presenta derecho de censura sobre los subsistemas científico-tecnológicos, sino de considerar que «es igualmente vital para la existencia del sistema global de nuestra civilización que la ciencia sea compatible con los principios morales de la humanidad, así como también que la moral y la ética sean adecuadas al nivel de nuestro conocimiento científico» (Agazzi, 1996, p. 301). El significado de estas apreciaciones finales es que, por razones puramente sistémicas, la tecnociencia no puede prescindir de su apertura a consideraciones de tipo moral, así como tampoco el sistema bioético puede mantenerse completamente ajeno a los outputs de la ciencia y la tecnología. Por supuesto, lo dicho no impide reconocer que la bioética es un subsistema en estrecho vínculo con el subsistema legal y así es esperable debido al carácter global y público de la empresa tecnocientífica. No obstante, se trata también de entender que el subsistema bioético ofrece puntos

\footnotetext{
16 Para profundizar en ella remitimos al lector a la obra de Evandro Agazzi (1996) titulada El bien, el mal y la ciencia: las dimensiones éticas de la empresa científico-tecnológica.
} 
de referencia externos ineludibles en los cuales la ciencia y la tecnología pueden encontrar los criterios racionales de las elecciones humanas allí tomadas, evitando de ese modo la absolutización de estos subsistemas y contrarrestando las influencias desmedidas que emanan de los subsistemas económicos y políticos.

\section{Consideraciones finales}

La conceptualización del nacimiento de los primeros seres humanos editados genéticamente como el malobrar de un científico-investigador reduce un problema ético de gran envergadura a un mero acto de desobediencia individual. Conduce, a su vez, a una búsqueda compulsiva por mejorar las regulaciones vigentes y reforzar los mecanismos de control y supervisión. Nombres propios, reconocimiento de infractores e imposición de normas son los resultados naturales de esta forma de entender la relación entre la tecnociencia y la ética.

En este artículo hemos procurado ofrecer una lectura alternativa del evento centrada en las condiciones de posibilidad que lo habilitaron e impulsaron. Desde esta perspectiva, el problema no puede reducirse a los motivos personales de quien comete una «infracción», sino que debe necesariamente contemplar las lógicas actuales de producción científica y tecnológica que fomentan acciones como las señaladas. Desde luego, estas consideraciones no eliminan los aspectos individuales y subjetivos de la dimensión moral. Sin embargo, reconocemos que se vuelve central visibilizar ciertas influencias de gran peso en la actualidad. Es únicamente en ese sentido que sostuvimos que la tecnología CRISPR/Cas9 responde a un tipo de racionalidad tecnocientífica, con un fuerte discurso publicitario asociado en el que se entretejen lógicas empresariales y pujas geopolíticas entre Estados. Así considerado, el acontecimiento, lejos de ser excepcional, se presenta fuertemente influenciado por una matriz de posibilidades tecnocientíficas de alcance global.

Para finalizar, cabe resaltar que este trabajo no condena ni niega en su totalidad los beneficios de la formulación e implementación de normas, sino que cuestiona que la bioética adopte dicha estrategia como principal medio de prevención de daños. Se trata, por otro lado, de reconocer la inherente pérdida de eficacia ética cuando, en virtud del mero cumplimiento de normativas externas, los científicos y biotecnólogos son exonerados de su capacidad de juzgar. Precisamente allí, donde el juicio aparece ausente, se encuentra el daño en potencia (Arendt, 2003 [1963]; Forti, 2015 [2012]). En ese espacio vacío de pensamiento aparecen sujetos que, en nombre del bien, son capaces de ocasionar el mal. La bioética aún tiene por delante el desafío de pensar 
cómo llenar ese vacío. El enfoque sistémico es una alternativa prometedora que apunta justamente en esa dirección.

\section{Conflicto de intereses}

Los autores declaran no tener ningún conflicto de intereses.

\section{Referencias}

Agazzi, E. (1987). A systems-theoretic approach to the problem of the responsibility of science. Zeitschrift für Allgemeine Wissenschaftstheorie, 18(1), 30-49. http://dx.doi.org/10.1007/BF01801076

Agazzi, E. (1996). El bien, el mal y la ciencia: las dimensiones éticas de la empresa científico-tecnológica. Madrid: Tecnos.

Albornoz, M. (2009). Indicadores de innovación: las dificultades de un concepto en evolución. Revista Iberoamericana de Ciencia, Tecnología y Sociedad, 5(3), 9-25.

Arendt, H. (2003 [1963]). Eichmann en Jerusalén. Un estudio sobre la banalidad del mal. Barcelona: Lumen.

Arendt, H. (2009 [1958]). La condición humana. Buenos Aires: Paidós.

Baltimore, B. D., Berg, P., Botchan, M., Carroll, D., Charo, R. A., Church, G. y ...Yamamoto, K. R. (2015). A prudent path forward for genomic engineering and germline gene modification. Science., 348, 36-38. http://dx.doi.org/10.1126/science.aab1028

Beijing Review. The Talent Magnet (2018) [consultado 19 Nov 2019]. Disponible en: http://www.bjreview.com/Nation/201805/t20180528_800130852.html

Bianchi, C. (2006). La innovación como objeto de estudio de la historia económica. Boletín de Historia Económica, 5, 32-44.

Bunge, M. (1966). Technology as applied science. Technology and Culture, 7(3), 329-347. http://dx.doi.org/10.2307/3101932

Charo, A. (2019). Rogues and Regulation of Germline Editing. The New England Journal of Medicine, 380(10), 976-980. http://dx.doi.org/10.1056/NEJMms1817528

Choe, H., Farzan, M., Sun, Y., Sullivan, N., Rollins, B., Ponath, P. D., Wu, L. y ...Sodroski, J. (1996). The $\beta$ chemokine receptors CCR3 and CCR5 facilitate infection by primary HIV-1 isolates. Cell., 85, 1135-1148. http://dx.doi.org/10.1016/S0092-8674(00)81313-6

Contreras, J. L. y Sherkow, J. S. (2017). CRISPR, surrogate licensing, and scientific discovery. Science. 355(6326), 698-700. http://dx.doi.org/10.1126/science.aal4222

Cyranoski, D. (2016). CRISPR gene-editing tested in a person for the first time. Nature., 539, 479. http://dx.doi.org/10.1038/nature.2016.20988

Davies, K. (2018). He Said What Now? The CRISPR Journal, 1(6), 358-362. http://dx.doi.org/10.1089/crispr.2018.29041.kda

Dickenson, D. y Darnovsky, M. (2019). Did a permissive scientific culture encourage the 'CRISPR babies' experiment? Nature Biotechnology, 37, 355-357. http://dx.doi.org/10.1038/s41587-019-0077-3

Digilio, P. (2017). Conocimiento y ética. Revista Debate Público. Reflexión de Trabajo Social, 13/14, 21-33.

Doudna, J. y Charpentier, E. (2014). The new frontier of genome engineering with CRISPR-Cas9. Science, 346(6213), 1258096. http://dx.doi.org/10.1126/science.1258096

Doudna, J. y Sternberg, S. (2017). A crack in creation: Gene editing and the unthinkable power to control evolution. Boston/Nueva York: Houghton Mifflin Harcourt.

Dyer, O. (2018). Researcher who edited babies' genome retreats from view as criticism mounts. $B M J, 363$, k5113. http://dx.doi.org/10.1136/bmj.k5113 
Echeverría, J. (2003). La revolución tecnocientífica. Madrid: Fondo de Cultura Económica.

Ellul, J. (1964 [1954]). The technological society. Nueva York: Vintage Books.

Forti, S. (2015 [2012]). New demons. Rethinking power and evil today. Stanford: Stanford University Press.

Gao, C. (2018). The future of CRISPR technologies in agriculture. Nature Reviews Molecular Cell Biology, 19, 275-276. http://dx.doi.org/10.1038/nrm.2018.2

Gumer, J. M. (2019). The wisdom of germline editing: An ethical analysis of the use of CRISPR-Cas9 to edit human embryos. The New Bioethics, 25(2), 137-152. http://dx.doi.org/10.1080/20502877.2019.1606151

Hsu, P. D., Lander, E. S. y Zhang, F. (2014). Development and Applications of CRISPR-Cas9 for Genome Engineering. Cell, 157, 1262-1278. http://dx.doi.org/10.1016/j.cell.2014.05.010

Jasanoff, S., Hurlbut, J. y Saha, K. (2015). CRISPR democracy: Gene editing and the need for inclusive deliberation. Issues in Science and Technology, 32(1), 25-32.

Jiankui, H., Ferrell, R., Yuanlin, C., Jinzhou, Q. y Yangran, C. (2018). Draft ethical principles for therapeutic assisted reproductive technologies. The CRISPR Journal, 1(6), 1-3. http://dx.doi.org/10.1089/crispr.2018.0051

Jinek, M., Chylinski, K., Fonfara, I., Hauer, M., Doudna, J. A. y Charpentier, E. (2012). A programmable dual-RNA-guided DNA endonuclease in adaptive bacterial immunity. Science, 337, 816-821. http://dx.doi.org/10.1126/science.1225829

Kitcher, P. (2001). Science truth, and democracy. Oxford: Oxford University Press.

Klimovsky, G. (1994). Las desventuras del conocimiento científico. Buenos Aires: AZ editora.

Krimsky, S. (2019). Ten ways in which He Jiankui violated ethics. Nature Biotechnology, 37, 19-20. http://dx.doi.org/10.1038/nbt.4337

Lander, E. S. (2016). The Heroes of CRISPR. Cell., 164, 18-28. http://dx.doi.org/10.1016/j.cell.2015.12.041

Lanphier, E., Urnov, F., Haecker, S. E., Werner, M. y Smolenski, J. (2015). Don't edit the human germ line. Nature, 519, 410-411. http://dx.doi.org/10.1038/519410a

Laudan, L. (1984). Science and values: the aims of science and their role in scientific debate. Berkeley: University of California Press.

Larrión Cartujo, J. (2011). Historia de las reuniones de Asilomar. Éxitos y fracasos de la autorregulación en las comunidades tecnocientíficas. Sociología y tecnociencia: Revista digital de sociología del sistema tecnocientífico, 1(1), 63-82.

Lederman, M. M., Penn-Nicholson, A., Cho, M. y Mosier, D. (2006). Biology of CCR5 and its role in HIV infection and treatment. JAMA, 296(7), 815-826. http://dx.doi.org/10.1001/jama.296.7.815

Liang, P., Xu, Y., Zhang, X., Ding, C., Huang, R., Zhang, Z. y ...Huang, F. J. (2015). CRISPR/Cas9-mediated gene editing in human tripronuclear zygotes. Protein Cell, 6(5), 363-372. http://dx.doi.org/10.1007/s13238-015-0153-5

Linares, J. (2008). Ética y mundo tecnológico. México D.F.: Fondo de Cultura Económica.

Linares, J. y Ayestarán, I. (2010). Racionalidad ética en un mundo tecnológico: hacia una ética reticular y policéntrica. Ludus Vitalis, 18(33), 229-244.

Ma, Y., Zhang, L. y Qin, C. (2019). The first genetically gene-edited babies: It's 'irresponsible and too early'. Animal Models and Experimental Medicine, 2(1), 1-4. http://dx.doi.org/10.1002/ame2.12052

Maddalo, D., Manchado, E., Concepcion, C. P., Bonetti, C., Vidigal, J. A., Han, Y. C. y ... Ventura, A. (2014). In vivo engineering of oncogenic chromosomal rearrangements with the CRISPR/Cas9 system. Nature, 516, 423-427. http://dx.doi.org/10.1038/nature13902

Mallapaty, S. (2018). Engineering a biomedical revolution. Nature, 564(7735), S66-S68. http://dx.doi.org/10.1038/d41586-018-07692-4

Normile, D. (2017). China sprints ahead in CRISPR therapy race. Science, 358(6359), $20-21$. http://dx.doi.org/10.1126/science.358.6359.20

Normile, D. (2018). Shock greets claim of CRISPR-edited babies. Science, 362, 978-979. http://dx.doi.org/10.1126/science.362.6418.978

OCDE. (1996). La innovación tecnológica: definiciones y elementos de base. REDES, 3(6), 129-176. 
Organizing Committee of the Second International Summit on Human Genome Editing. En Human Genome Editing II. National Academies of Sciences, Engineering, Medicine. (2018) [consultado 19 Nov 2019]. Disponible en http://www8.nationalacademies.org/onpinews/newsitem.aspx?RecordID=1282018b

Pallitto, N. y di Pasquo, F. (2017). El espíritu (tecno)científico que convendría evitar y resistir. Ludus Vitalis, 25(47), 261-264.

Pestre, D. (2005). Ciencia, dinero y política. Buenos Aires: Nueva Visión.

Platt, R. J., Chen, S., Zhou, Y., Yim, M. J., Swiech, L., Kempton, H. R. y ...Zhang, H. (2014). CRISPR-Cas9 knocking mice for genome editing and cancer modeling. Cell, 159(2), 440-455. http://dx.doi.org/10.1016/j.cell.2014.09.014

Rong, Z., Zhu, S., Xu, Y. y Fu, X. (2014). Homologous recombination in human embryonic stem cells using CRISPR/Cas9 nickase and a long DNA donor template. Protein Cell, 5(4), 258-260. http://dx.doi.org/10.1007/s13238-014-0032-5

Rose, H. y Rose, S. (2013). Genes, cells and brains: the promethean promises of the new biology. Londres: Verso.

Saada A. (2008). Prólogo. En J.C. Tealdi (Director), Diccionario Latinoamericano de Bioética (pp. xix-xxii). Bogotá: UNESCO - Red Latinoamericana y del Caribe de Bioética.

Sánchez-Rivera, F. J., Papagiannakopoulos, T., Romero, R., Tammela, T., Bauer, M. R., Bhutkar, A. y . . Jacks, T. (2014). Rapid modelling of cooperating genetic events in cancer through somatic genome editing. Nature, 516, 428-431. http://dx.doi.org/10.1038/nature13906

Sharif, N. y Tang, H. H. H. (2014). New trends in innovation strategy at Chinese universities in Hong Kong and Shenzhen. International Journal of Technology Management, 65(1/2/3/4), 300-318. http://dx.doi.org/10.1504/IJTM.2014.060951

Sherkow, J. S. (2016). Who owns gene editing? Patents in the time of CRISPR. Biochemist, 38, 26-29.

Sherkow, J. S. (2018). The CRISPR patent landscape: past present, and future. The CRISPR Journal, 1(1), 1-5. http://dx.doi.org/10.1089/crispr.2017.0013

Sternberg, S. H. y Doudna, J. (2015). Expanding the Biologist's Toolkit with CRISPR-Cas9. Molecular Cell, 58, 568-574. http://dx.doi.org/10.1016/j.molcel.2015.02.032

Wang, C., Zhai, X., Zhang, X., Li, L., Wang, J., Liu, D. P., \& Chinese Academy of Medical Sciences. (2019). Gene-edited babies: Chinese Academy of Medical Sciences' response and action. The Lancet, 393, 25-26. http://dx.doi.org/10.1016/S0140-6736(18)33080-0

Wright, A. V., Nuñez, J. K. y Doudna, J. (2016). Biology and applications of CRISPR systems: Harnessing nature's toolbox for genome engineering. Cell, 164, 29-44. http://dx.doi.org/10.1016/j.cell.2015.12.035

Zhang, B., Chen, Z., Yi, J., Tang, H., Wang, C., \& Chinese Academy of Engineering. (2019). Chinese Academy of Engineering calls for actions on the birth of gene-edited infants. The Lancet, 393, 25. http://dx.doi.org/10.1016/S0140-6736(18)33081-2

Zhang, B. y Lie, R. K. (2018). Ethical issues in human germline gene editing: a perspective from China. Monash Bioethics Review, 36(1), 23-35. http://dx.doi.org/10.1007/s40592-018-0091-0

Zhou, M., Greenhill, S., Huang, S., Silva, T. K., Sano, Y., Wu, S. y ...Silva, A. J. (2016). CCR5 is a suppressor for cortical plasticity and hippocampal learning and memory. Elife, 5, e20985. http://dx.doi.org/10.7554/eLife.20985 